\title{
PURIFICAÇÃO DE BIODIESEL ETÍLICO E METÍLICO UTILIZANDO MEMBRANA POLIMÉRICA
}

\author{
I. V. CAVALCANTI ${ }^{1}$, M. J. ALVES ${ }^{1}$, M. I. MARTINS ${ }^{1}$, V. L. CARDOSO ${ }^{1}$ e M. H. M. \\ REIS ${ }^{1}$
}

1 Universidade Federal de Uberlândia, Faculdade de Engenharia Química

E-mail para contato: magno.caxote@gmail.com

\begin{abstract}
RESUMO - No processo de produção do biodiesel, a etapa de lavagem com água é uma das etapas que requerem maior preocupação, fato este devido às grandes quantidades de água limpa utilizada, resultando em grandes quantidades de efluentes a serem tratados. Assim, neste trabalho propomos a utilização de microfiltração com membranas de $0,05 \mu \mathrm{m}$ e pressão transmembrana de $2,5 \mathrm{bar}$, para a purificação do biodiesel etílico e metílico. Os resultados obtidos para os parâmetros densidade, viscosidade e índice de acidez do biodiesel microfiltrado se encontraram dentro dos limites estabelecidos pela legislação vigente. A adição de $0,1 \%$ e $0,2 \%(\mathrm{~m} / \mathrm{m})$ de água ao biodiesel metílico antes do processo de filtração favoreceu a remoção da glicerina.
\end{abstract}

\section{INTRODUÇÃO}

A maior parte de toda a energia consumida no mundo provém do petróleo, do carvão e do gás natural, que são combustíveis fosseis não renováveis. A busca por fontes de energia menos impactantes ao meio ambiente e a possibilidade de esgotamento das reservas de petróleo de fácil extração, têm incentivado a utilização de insumos renováveis, que possam substituir, ao menos parcialmente, os combustíveis de origem fóssil.

O biodiesel é um éster graxo produzido pela reação de transesterificação, na qual ocorre a transformação dos triglicerídeos provenientes de óleos vegetais, gordura animal ou ainda óleo residual, em moléculas menores de ésteres de ácidos graxos (Dorado et al., 2004; Brasil, 2005).

A reação de transesterificação tem como objetivo principal a diminuição da viscosidade da matéria-prima, atingindo valores que permitam a utilização do produto obtido em máquinas de ignição, como os tradicionais motores a diesel. (Freedman et al., 1986).

O nível de pureza do biodiesel tem fortes efeitos na sua utilização como combustível. Particularmente, a presença de gicerídeos e triglicerídeos no combustível podem causar sérios problemas de aplicação. De fato, o combustível deve ser livre de água, álcool, glicerina e catalisador. De acordo com os padrões da União Européia, o biodiesel deve ter uma pureza mínima de 96,5\% com relação a presença de ácidos graxos livres, álcool, glicerina e água (Karaosmanoglu et al., 1996). A resolução 45/2014 da Agencia Nacional do Petróleo 
regulamenta que o biodiesel produzido no Brasil não pode ter mais que $0,02 \%$ em massa de glicerol livre.

Atualmente, as etapas de purificação aplicadas para o biodiesel cru, obtidos após a reação de transesterificação, são dispendiosas, além da restrição ambiental pelo consumo de água de lavagem e geração de uma quantidade significativa de efluente. Desta forma, faz-se necessário a busca por alternativas para a purificação efetiva do biodiesel. Assim, o objetivo deste trabalho é avaliar o potencial de aplicação de membranas de microfiltração para a purificação de biodiesel etílico e metílico, além de verificar a influencia da adição de pequenas quantidades de água ao biodiesel antes de sua filtração, com o propósito de efetivar a retenção da glicerina pela membrana.

\section{METODOLOGIA}

\subsection{Produção do biodiesel}

Neste trabalho foram utilizados os biodieseis etílicos e metílicos. O biodiesel metílico foi gentilmente cedido pela empresa CARAMURU ALIMENTOS S.A (São Simão - GO). Este biodiesel foi coletado pela empresa na etapa posterior a decantação, ou seja, antes de ser purificado pelo processo tradicional com água. Este biodiesel é denominado no trabalho de biodiesel cru.

O biodiesel etílico utilizado foi produzido com óleo de soja refinado como matériaprima. A razão molar óleo:etanol utilizado foi de $1: 12 \mathrm{com} 75 \%$ (base mássica) de hidróxido de potássio como catalisador a temperatura de $40^{\circ} \mathrm{C}$ no período de uma hora. A reação foi conduzida em um reator de $2 \mathrm{~L}$ inserido em uma manta aquecedora com agitação mecânica (Figura 1). Ao término de cada reação, o conteúdo reacional foi colocado em um rotaevaporador acoplado a uma bomba a vácuo $(350 \mathrm{mmHg})$ e a banho com temperatura de aproximadamente $90^{\circ} \mathrm{C}$ para recuperar o excesso de etanol. O conteúdo foi transferido então para um funil para separação das fases éster e glicerina. O tempo de decantação foi de 12 horas. A fase éster obtida após o processo de decantação será denominada de biodiesel cru.

Figura 1 - Reator utilizado na reação de transesterificação

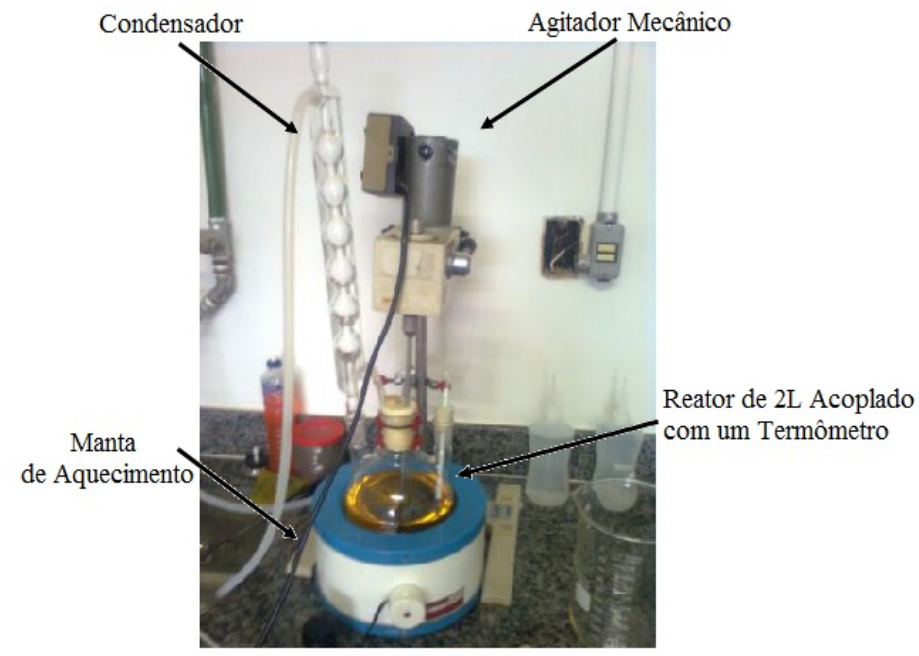




\subsection{Purificação utilizando membranas}

Neste trabalho foi utilizado um módulo de filtração batelada, que fez uso da operação do tipo perpendicular. Nesse tipo de filtração, o permeado passa através da membrana e o soluto, ou os materiais em suspensão, são retirados na superfície da membrana. No módulo foram utilizadas membranas comerciais (Microdyn Technologies Inc, USA) polimérica de microfiltração planas, de $0,05 \mu \mathrm{m}$, com pressão transmembrana de 2,5 bar. Esta pressão foi escolhida por meio de testes preliminares em que foi verificado um fluxo satisfatório através da membrana.

Além das filtrações do biodiesel cru, testes adicionais foram realizados com a adição de pequenas quantidades de água no biodiesel cru antes da filtração. Água deionizada foi adicionada à amostra de biodiesel, em concentrações $0,1 \%$ e $0,2 \%$ em peso. A mistura de água e biodiesel foi agitada durante 1 hora à temperatura ambiente utilizando um agitador magnético.

\subsection{Lavagem com água destilada}

De acordo com Alves e Torres (2007), no processo de lavagem de biodiesel são retirados o excesso de catalisador, álcool, glicerina livre residual, ácidos graxos, tri, di e mono glicerídeos.

Para fins comparativos, o biodiesel cru também foi purificado pelo processo tradicional de lavagem com água. Para tanto, utilizou-se água destilada aquecida a $50^{\circ} \mathrm{C}$ a uma razão de 1:1 em volume (água:biodiesel) para a lavagem do biodiesel (He et al., 2006). Esta lavagem foi repetida 3 vezes. $\mathrm{O}$ pH da água de lavagem foi monitorado para garantir sua neutralidade. Posteriormente o biodiesel foi adicionado em sulfeto de sódio anidro ( $25 \%$ do peso do biodiesel) para a secagem.

\subsection{Caracterização do biodiesel}

A caracterização do biodiesel cru, lavado e permeados, envolveu os parâmetros viscosidade, densidade, glicerina livre, teor de umidade e índice de acidez.

Para medir a densidade do biodiesel foi utilizado um densímetro graduado em unidades de massa específica de bulbo simétrico calibrado a $20^{\circ} \mathrm{C}$, de acordo com a norma ABNT NBR 7148. O teor glicerina livre presente no biodiesel foi determinado pelo método cromatográfico descrito na norma ASTM - D 6584 (Cromatografo Gasoso - Shimadzu-GC-2010 Plus). Já o índice de acidez foi obtido de acordo com a metodologia do Instituto Adolfo Lutz (2008). O teor de umidade foi determinado conforme a norma EN ISO12937 utilizando um Karl Fischer (Metrohm-756 Karl Fischer) e a viscosidade dinâmica foi medida a $40^{\circ} \mathrm{C}$ e a $40 \mathrm{~s}^{-1}$ utilizando um viscosímetro digital de bancada da marca Brookfield modelo DV - III Ultra.

\section{RESULTADOS E DISCUSSÃO}

$\mathrm{Na}$ Tabela 1 estão demonstrados os resultados obtidos nas análises dos biodieseis etílicos e metílicos crus, lavados e permeados para os parâmetros índice de acidez, viscosidade, densidade, teor de umidade e glicerina livre. 
Tabela 1 - Caracterização físico-química dos biodieseis crus, lavados e permeados.

\begin{tabular}{|c|c|c|c|c|}
\hline $\begin{array}{c}\text { Amostra de } \\
\text { Biodiesel }\end{array}$ & $\begin{array}{c}\text { Densidade } \\
\left(\mathrm{Kg} / \mathrm{m}^{3} \mathrm{a}\right. \\
\left.20^{\circ} \mathrm{C}\right)\end{array}$ & $\begin{array}{c}\text { Viscosidade } \\
\left(m P a . s 40 s^{-1} 40^{\circ} \mathrm{C}\right)\end{array}$ & $\begin{array}{c}\text { Índice de } \\
\text { acidez } \\
\text { (mgKOH/g) }\end{array}$ & $\begin{array}{c}\text { Glicerina } \\
\text { livre } \\
(\% \mathrm{~m} / \mathrm{m})\end{array}$ \\
\hline Metílico (cru) & 0,872 & 4,7 & 0,14 & 0,845 \\
\hline Metílico (lavado) & 0,876 & 4,5 & 0,25 & 0,003 \\
\hline $\begin{array}{l}\text { Metílico } \\
\text { (permeado) }\end{array}$ & 0,880 & 4,8 & 0,08 & 0,062 \\
\hline $\begin{array}{c}\text { Metílico 0,1\% } \\
\mathrm{H}_{2} \mathrm{O} \text { (permeado) }\end{array}$ & 0,872 & 4,4 & 0,10 & 0,014 \\
\hline $\begin{array}{c}\text { Metílico 0,2\% } \\
\mathrm{H}_{2} \mathrm{O} \text { (permeado) }\end{array}$ & 0,880 & 4,2 & 0,11 & 0,005 \\
\hline Etílico (cru) & 0,880 & 4,4 & 0,11 & 0,744 \\
\hline Etílico (lavado) & 0,882 & 4,5 & 0,27 & 0,001 \\
\hline Etílico (permeado) & 0,880 & 4,4 & 0,14 & 0,389 \\
\hline $\begin{array}{c}\text { Etílico } 0,1 \% \mathrm{H}_{2} \mathrm{O} \\
\text { (permeado) }\end{array}$ & 0,882 & 4,2 & 0,13 & 0,349 \\
\hline $\begin{array}{l}\text { Etílico } 0,2 \% \mathrm{H}_{2} \mathrm{O} \\
\text { (permeado) }\end{array}$ & 0,878 & 4,6 & 0,12 & 0,325 \\
\hline
\end{tabular}

A densidade do biodiesel cru produzido já estava dentro dos padrões definidos pela Resolução 45/2014, nenhuma das metodologias de purificação utilizadas alterou alterou essa condição.

A norma vigente da ANP determina que a viscosidade dinâmica deva estar entre 2,64 e $5,28 \mathrm{mPa} \mathrm{s}$ a $40 \mathrm{~s}^{-1}$ e a $40^{\circ} \mathrm{C}$, desta maneira o biodiesel cru e os biodieseis purificados pelos dois métodos de refino se encontram dentro dos limites da ANP.

$\mathrm{O}$ índice de acidez permitido pela agência reguladora do biodiesel deve ser inferior a 0,5 $\mathrm{mg} \mathrm{KOH} \mathrm{g}^{-1}$. Tanto o biodiesel cru quanto os purificados já estão dentro desta faixa, não sendo necessário nenhum tratamento para neutralização. 
O biodiesel cru não se enquadrou dentro do limite estabelecido pela ANP, enquanto que a lavagem conseguiu diminuir o teor de glicerina livre até o limite estabelecido (menor que $0,02 \%)$. Os resultados apresentados na Tabela 1 mostram que a membrana de microfiltração com tamanho de poro de $0,05 \mu \mathrm{m}$ apesar de diminuir o teor de glicerina livre, não foi eficiente para enquadrar o biodiesel ao limite estabelecido pela ANP.

A adição de pequenas quantidades de água, nas concentrações de $0,1 \%$ e $0,2 \%$, resultou em uma redução satisfatória do teor de glicerina livre (menor que $0,02 \%$ ) para o biodiesel metílico, mas não foi eficiente para o biodiesel etílico.

\section{CONCLUSÃO}

Os valores obtidos para os parâmetros densidade, viscosidade e índice de acidez das amostras de biodiesel, etílico e metílico, puficados pelos processos de lavagem com água e de microfiltração se encontram dentro limites estabelecidos pela legislação vigente. A membrana de $0,05 \mu \mathrm{m}$ não foi capaz de produzir um biodiesel purificado de acordo com os parâmetros exigidos pela legislação, apesar de ter removido parte da glicerina presente no biodiesel cru. A adição de $0,1 \%$ e $0,2 \%$ em peso de água nos biodieseis antes da filtragem aumentou significativamente a remoção da glicerina, mas apenas o biodiesel metílico se enquadrou no limite estabelecido pela ANP. Esses resultados demonstram que o processo de separação por membrana é uma alternativa viável para a purificação de biodiesel, contudo, tamanhos de poros mais específicos e diferentes tipos de membranas devem ser analisados com o intuito de atender a legislação e alcançar uma melhor viabilidade econômica.

\section{REFERÊNCIAS}

ABNT - ASSOCIAÇÃO BRASILEIRA DE NORMAS TÉCNICAS. ABNT NBR 7148: Petróleo e produtos de petróleo - determinação da massa específica, densidade relativa e ${ }^{\circ}$ API - Método do densímetro. 2006.

ALVES, C.T.; TORRES, E.A. Otimização do Processo de Lavagem da Planta Piloto de Biodiesel da UFBA II Congresso da Rede Brasileira de Tecnologia de Biodiesel, p.150150, Brasilia, 2007.

ARNOT, T.C.; FIELD, R.W.; KOLTUNIEWICZ, A.B. Cross-flow and dead-end microfiltration of oily-water emulsions. J. Memb. Sci. 169, 2000, 1-15.

ASSOCIAÇÃO BRASILEIRA DE NORMAS TÉCNICAS. NBR 7148 :Petróleo e Produtos de Petróleo - Determinação da massa específica, densidade relativa e API - Método do densímetro, $2009 \ldots$

ASTM - AMERICAN SOCIETY FOR TESTING AND MATERIALS. D 6584: Determination of Free and Total Glycerine in Biodiesel Methyl Esters by Gas Chromatography, 2007. 18p.

DORADO, M.P.; BALLESTEROS, E.; LÓPEZ, F.J.; MITTELBACH, M.. Optimization of alkali-catalyzed transesterification of Brassica carinata oil for biodiesel production. Energ. \& Fuel., 18, 2004,77-83. 
FREEDMAN, B., BUTTERFIELD, R.O.; PRYDE, E.H. Transesterification kinetics of soybean oil. J. Am. Oil Chem. Soc., 63, 1357-1380, 1986.

HE, H.Y.; GUO, X.; ZHU, S.L. Comparison of membrane extraction with traditional extraction methods for biodiesel production. JAOCS, v. 83, p. 457-460, 2006.

KARAOSMANOGLU, F.; CIGIZOGLU, K.B.; TUTER, M.; ERTEKIN, S. Investigation of the Refining Step of Biodiesel Production. Energy \& Fuels, v.10, n.4, p. 890-895, July 1996. 